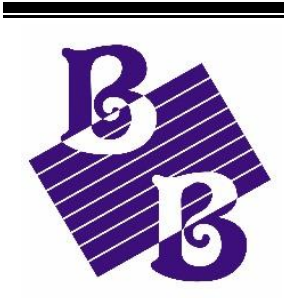

BioBacta

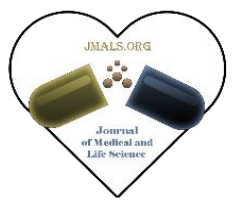

Journal of Medical and Life Science www.jmals.journals.ekb.eg

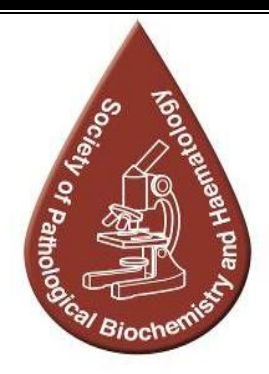

\title{
Using Egyptian fruit bat (Rousettus aegyptiacus) as a bioindicator of environmental health, across some Egyptian Governorates.
}

\author{
Basma M. Sheta ${ }^{1}$ and Mokhtar S. Beheary ${ }^{2}$ \\ ${ }^{1}$ Zoology Department, Faculty of Science, Damietta University, PO Box 819, 34517 New Damietta, Damietta, Egypt. \\ ${ }^{2}$ Environmental Science Department, Faculty of Sciences, Port Said University, Egypt. \\ *Corresponding author. E-mail address: basmasheta@du.edu.eg \\ Received April, 15, 2019; Accepted May ,16,2019
}

\begin{abstract}
:
Bats are a good animal model of monitoring habitat pollution by heavy metal concentration assessment. A total of 50 Egyptian fruit bat were sampled from five governorates: Beni Suef, Damietta, Fayoum, Giza and Menofia. Fur samples were collected from these bats to be tested for the presence of heavy metals by using Atomic Absorption Spectrophotometry. Seven heavy metals (manganese (Mn), zinc ( $\mathrm{Zn})$, cadmium (Cd), chromium (Cr), Ferrum $(\mathrm{Fe})$, nickel $(\mathrm{Ni})$, and lead $(\mathrm{Pb})$ ) have been estimated. Statistical analysis with One-Way Analysis of Variance (ANOVA) revealed a significant difference of heavy metals concentration in the fur of bats at different studied governorates. No statistically differences in fur metals were observed between males and females fruit bat, except for $\mathrm{Pb}$. No, correlation was observed between bat heaviness and fur heavy metals content. This study confirms bat fur as a biomarker for heavy metal contamination. The results showed that Beni Suef samples were the most contaminated with different heavy metals among the other governorates, followed by Damietta samples. Bats from Menofia and Fayoum governorates were the cleanest.
\end{abstract}

Key words: Egyptian fruit Bat, Fur, heavy metals.

\section{Introduction:}

Bats are considered as one of the ideal bioindicators of heavy metal toxicity assessment in the environment and habitat quality (Wickramasinghe et al., 2004; Kalcounis-Rueppell et al., 2007, Hernout et al., 2016), especially by exploiting their fur to estimate the heavy metal exposure (Åkerblom \& de Jong, 2017). Bats have a relatively long life span, higher metabolic rate and their feeding habits lead to accumulation of heavy metals from the surrounding environment (Hickey et 
al., 2001). Moreover, bats occupy a wide habitat range which makes it a good bioindicator. (Jones et al., 2009). The Egyptian fruit bat (Rousettus aegyptiacus) is a small mammal belongs to order (Chriopetra) the second-largest mammalian order (1,250 species) (Lučan et al., 2014). It is a fruit eater and has an important ecological role as a pollinator (HerzigStraschil \& Robinson 1978; Monadjem et al. 2010; Kunz et al. 2011), characterized by their ability to perform true flight (Payne et al., 1985). Egyptian fruit bat has a great wide range in the Palearctic zone, including the Middle East (Benda et al., 2012). In Egypt, the Egyptian fruit bat is widely distributed across Nile Delta and Valley, the fruit availability is the main determinant factor to its presence in a specific habitat. Collectively, all previous factors make it as the best bioindicator to study the pollution among different habitat in Egypt.

Naturally, heavy metals exist from natural resources in the soil, water and organisms, however, anthropogenic activities and related pollution increase these metals ( $\mathrm{Li}$ et al. 2014). Beyersmann and Hartwig (2008) identified that arsenic (As), cadmium (Cd), cobalt (Co), chromium $(\mathrm{Cr})$, copper $(\mathrm{Cu})$, mercury $(\mathrm{Hg})$, manganese $(\mathrm{Mn})$, nickel $(\mathrm{Ni})$, lead $(\mathrm{Pb})$, tin $(\mathrm{Sn})$ and thallium(TI) as the most eleven elements with high risk to wildlife. It has been proven that continuous exposure to heavy metals one of the major factors in current bat populations decline (Mickleburgh et al. 2002).

Unconventional sampling methods of heavy metal risk assessment, like a sampling of fur, feathers, hair, and claw are required especially for threatened or protected species. (Dauwe et al., 2000; D'Have et al., 2006). The regular methods like blood sampling or even killing for taking tissues are more damaging and in the long run affect the population's fitness (D'Have et al., 2006). Fur sampling is one of the best examples of non-traditional methods as it is easy to collect and its storage doesn't require subsequent procedures (Appenzeller and Tsatsakis, 2012). Reliable information can result from fur analysis as heavy metal can be excreted from blood to fur during the living organism's growth (Kales and Christiani, 2005, Beernaert et al., 2007). Previous research has proven that fur or hair analysis can demonstrate metal bioavailability in the environment (McLean et al., 2009; Nolet et al., 1994; Pereira et al., 2004; Marcheselli et al., 2010). Also, hair has been known as a biomarker in human studies (Kales and Christiani, 2005) and mammalian wildlife as well (McLean et al., 2009; Pereira et al., 2006; Beernaert et al., 2007). In wild mammals, positive correlations have been examined between concentrations of metals in hair and blood (Vermeulen et al., 2009) and concentrations in kidneys, liver, and muscle (Beernaert et al., 2007; Pereira et al., 2006; D'Have et al., 2006; Marcheselli et al., 2010). It has been proven (Hernout et al, 2016) that fur analysis of bat can give credible data of non-essential metals in the environment.

In the present work, the level of heavy metals concentration in the fur of Egyptian fruit bat from five different Governorates was assessed. The main objective was to compare the residue of the measured metal in relation to its environment.

\section{Material and methods:}

Bat samples were done from January to May 2018. A total of 50 Egyptian fruit bat individuals, comprising 10 from each site, were collected from five Governorates across the Nile Delta region, which are Beni Suef, Damietta, Menofia, Fayoum and Giza (Fig. 1). All bat colonies were lived in old abandoned houses mainly in 
rural areas near to humans. Bats capturing were done by mist-netting. Bats were not killed for the purposes of this study. Fur sample was collected from the belly and back, as close to the skin without cutting the bat. Samples were stored in envelops and kept frozen ($18^{\circ} \mathrm{C}$ ) till analysis. Fur was analyzed for the following heavy metals concentration: manganese $(\mathrm{Mn})$, zinc $(\mathrm{Zn})$, cadmium $(\mathrm{Cd})$, chromium $(\mathrm{Cr})$, Ferrum $(\mathrm{Fe})$, nickel $(\mathrm{Ni})$, lead $(\mathrm{Pb})$ using Inductively Coupled Plasma Emission Spectrometer (ICPS) -7510. The fur analysis was done described in detail in our previous work (Sheta et al, 2019).

Differences in heavy metals concentration in the fur of Egyptian fruit bat among the study sites were conducted by one-way analysis of variance (ANOVA). All tests were evaluated for significance at $\mathrm{p}<0.05$. When ANOVA was significant, a post-hoc test using a t-test was applied to compare data of each 2 governorates. The difference was considered significant when $\mathrm{p}<0.05$. Statistical calculations were done using Microsoft excel in 2010. The mean heavy metal concentrations were showed as mean \pm standard error of the mean (SEM) in ppm.

Correlation between different fur metal concentrations and animal body weight values was assessed using the Spearman rank correlation coefficient.

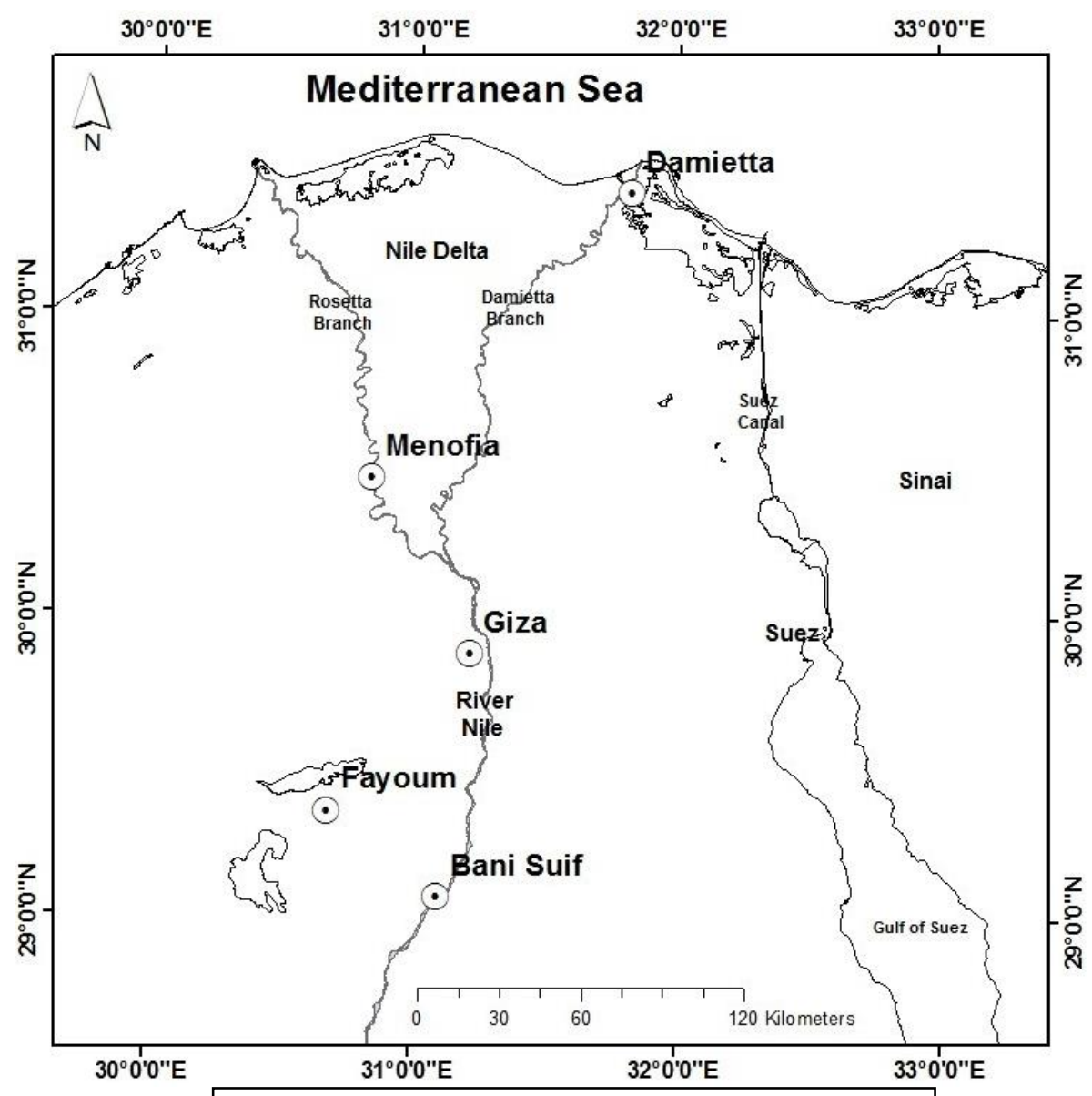

Fig. 1. Map of study sites across 5 governorates 


\section{Results and Discussion:}

One of the main important criteria that makes bat as a very good bioindicator is that bats coexist with humans habitats like industrial, rural and urban which increase the threat of heavy metal contamination by different human activity (Gaisler et al. 1998; Bartonička and Zukal, 2003). Thus, bats were studied to assess heavy metal concentration in fur, which should be correlative to their inhabiting environment.

The mean concentration of the seven heavy metals elements $\mathrm{Mn}, \mathrm{Zn}, \mathrm{Cd}, \mathrm{Cr}, \mathrm{Fe}, \mathrm{Ni}$ and $\mathrm{Pb}$ across the study sites shown in (Fig 2). The most abundant element in all study sites was Fe. In fact, we measured iron concentration to prove the fur as a biomarker for metal contamination, but not because iron is a toxic heavy metal. The theory is that these bats were collected from old houses that have many exposed roasted iron bars, and bats were in continuous contact with these bars. The highest iron concentration was recorded in Beni Suef (14.762 \pm 2.819$)$, which is in agreement with the results of other metals, too. This may indicate more contact with iron-contaminated places than in the other governorates. The other elements showed much lower concentration values. The result of level concentration heavy metals detected in all five study sites show the same order: $\mathrm{Fe}>\mathrm{Zn}>\mathrm{Mn}>\mathrm{Cr}>\mathrm{Cd}>\mathrm{Pb}>\mathrm{Ni}$.

One-way Analysis of Variance (ANOVA) showed that there are significant differences of all heavy metals concentration in Egyptian fruit bat between different study sites $(\mathrm{p}=0.0004,0.0002,0.04,0.02,0.003,0.03$, and 0.02 for $\mathrm{Mn}, \mathrm{Zn}, \mathrm{Cd}, \mathrm{Cr}, \mathrm{Fe}, \mathrm{Ni}$, and $\mathrm{Pb}$, respectively).

Post-hoc analysis using the t-test showed that $\mathrm{Mn}$ concentration in Beni Suef bats was significantly higher than that in all other governorates $(\mathrm{p}<0.05)$. The same result was found for $\mathrm{Zn}$ concentration since Beni Suef bat showed significantly higher $\mathrm{Zn}$ than that in other governorates. However, the values in Damietta were significantly higher than those in Menofia and Fayoum samples.

Beni Suef recorded the highest value of $\mathrm{Cd}$ concentration, which was significantly higher than in other governorates, while the value of Fayoum bats was significantly lower than the others. Also, Beni Suef showed higher values of $\mathrm{Cr}$ concentration than the other governorates. However, these values were only significant when compared to the values of Fayoum and Giza. The results of Fe showed that samples from Beni Suef were the most contaminated, while Fayoum Fe values were significantly lower than the values of other governorates.

$\mathrm{Ni}$ showed its highest concentrations in Beni Suef and Damietta. However, its values were only significantly higher when compared with Fayoum and Giza values. Lead has been detected in higher concentrations in both Damietta and Beni Suef. $\mathrm{Pb}$ values in bat fur from Fayoum and Giza were significantly lower than that from Damietta and Beni Suef.

The obtained results of this study showed that fur samples of bats reflected heavy metal variations among different governorates, which means the suitability of using it for environmental pollution monitoring. This is in accordance with previous studies on heavy metals monitoring in bat's fur (Hernout et al., 2016, Åkerblom $\&$ de Jong, 2017). Among the seven heavy metals, Fe recorded the highest concentration values. This may be explained by that animals might consume or exposed to iron $(\mathrm{Fe})$ whether by feeding on contaminated food or inhabit polluted habitat (Ma, 1996). The variation of heavy metals among different governorates reflects different human activities and how this affects wildlife. Beni Suef recorded the highest polluted governorates followed by Damietta. Attention should be paid mainly for these two governorates and the nature of pollution control. Also, more research should be done to assess the exposure risk of these metals on the bat population, wildlife, and human as well.

Increasing body weight did not correlate to more fur heavy metal content. Correlations between fur metal concentrations and body weight are shown in figure 3 . The most obvious correlation was found between body weight and $\mathrm{Zn}\left(\mathrm{R}^{2}=0.4\right)$ followed by $\mathrm{Pb}\left(\mathrm{R}^{2}=0.3\right)$. However, $\mathrm{R}^{2}$ values indicated a weak correlation between both variants. 

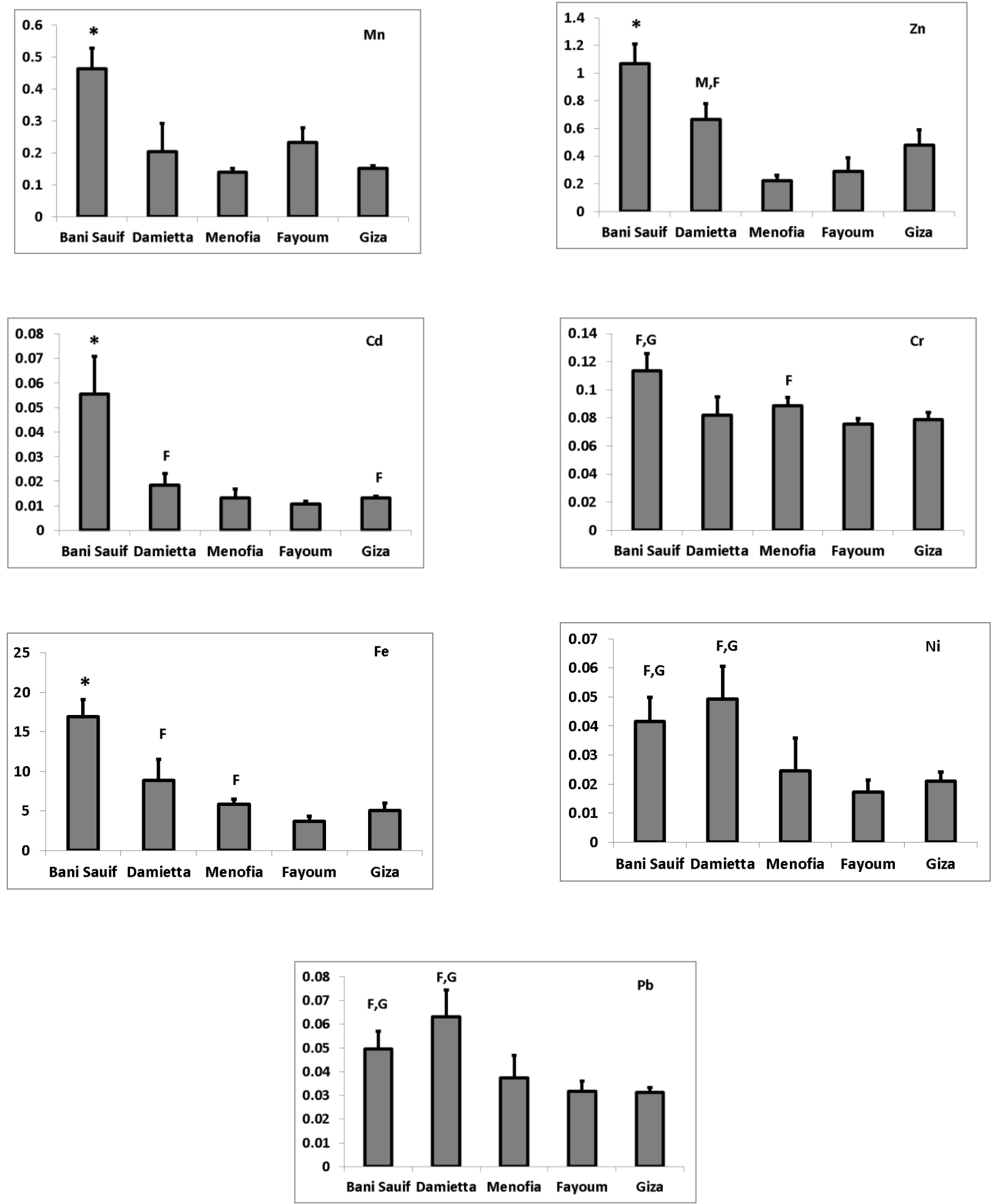

Fig. 2. Heavy metal content in Egyptian fruit bat fur across five governorates. Data are presented as mean \pm SEM of $\mathrm{N}=10$ samples from each governorate. Statistical Analysis: ANOVA: $\mathrm{p}<0.05$ in each sub-figure. Post-hoc ttest: * denotes significantly higher value $(\mathrm{p}<0.05)$ than all other values; the letters $\mathrm{M}, \mathrm{F}$ and $\mathrm{G}$ denote that this value is significantly higher than values of Menofia, Fayoum and Giza, respectively. 

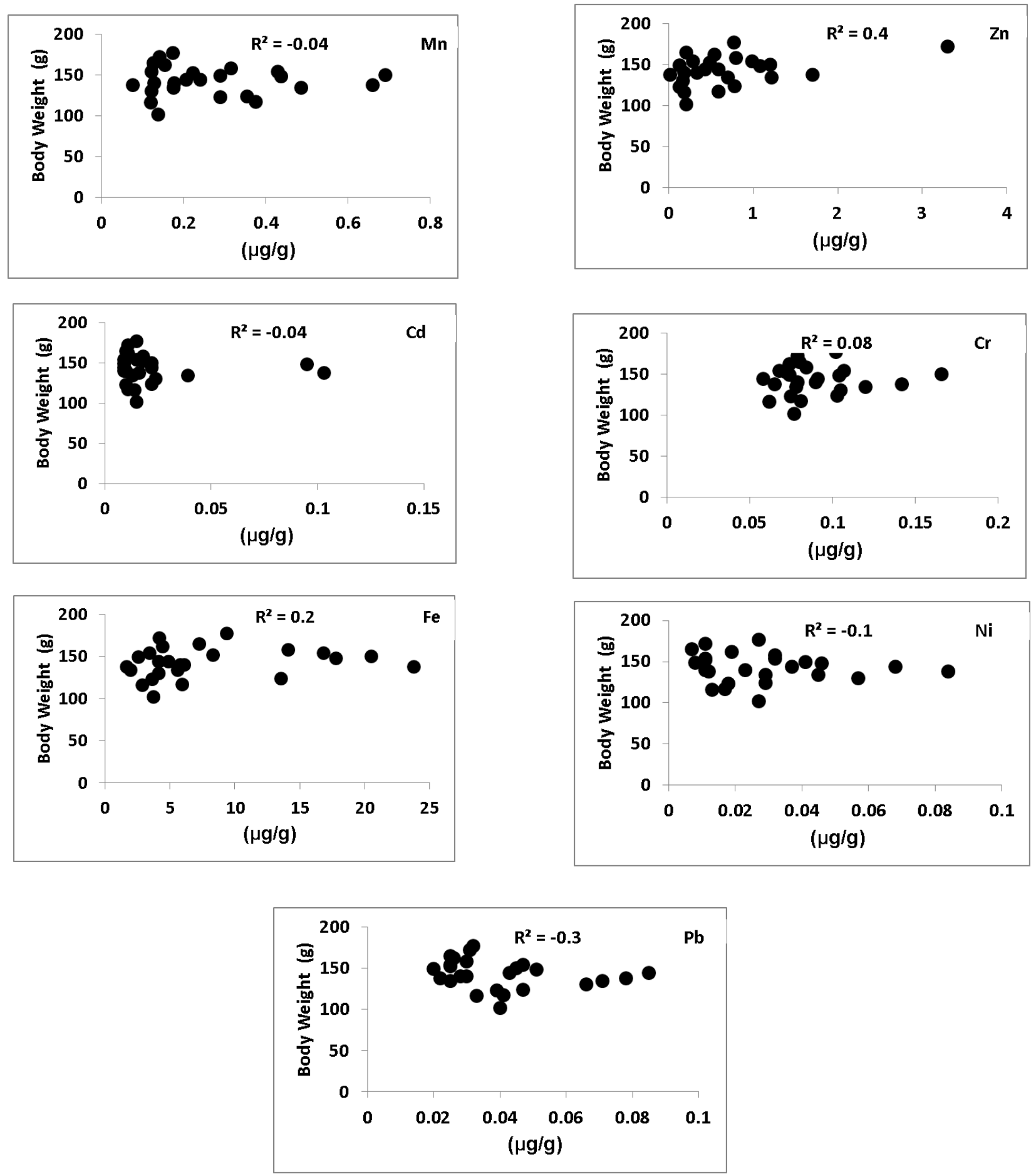

Fig. 3. Scatterplots of correlation between Fur metals concentrations and body weight in Egyptian Fruit bats across the studied governorates. 
As well, the study showed (Table 1) no statistically differences in fur content of heavy metals between males and females, except for $\mathrm{Pb}(\mathrm{p}=0.03)$. We thought to determine such variation of metal concentrations in both males and females since it was reported that females forage non-significantly more than males do (Barclay \& Jacobs, 2011). However, there was no significant difference between the sexes in this study.
In conclusion, fur samples of the Egyptian fruit bat can act as a good bioindicator for environmental pollution in Egypt. The results showed that there is a significant difference in studied heavy metal concentrations among the studied governorates. Beni Suef and Damietta governorates showed the highest values of the studied seven metals. More research should be done about the effect of this on wildlife and human as well.

Table (1): Average concentrations of heavy metals difference between male and females Egyptian fruit bat. "dw: dry weight".

\begin{tabular}{c|c|c|c}
\hline \multicolumn{2}{c}{ Male $\left(\mathrm{mg} \mathrm{kg}^{-1}, \mathrm{dw}\right)$} & Female $\left(\mathrm{mg} \mathrm{kg}^{-1}, \mathrm{dw}\right)$ & P value \\
\hline $\mathrm{Mn}$ & $0.234 \pm 0.039$ & $0.291 \pm 0.049$ & 0.205 \\
$\mathrm{Zn}$ & $0.639 \pm 0.115$ & $0.583 \pm 0.12$ & 0.382 \\
$\mathrm{Cd}$ & $0.021 \pm 0.006$ & $0.023 \pm 0.006$ & 0.450 \\
$\mathrm{Cr}$ & $0.083 \pm 0.004$ & $0.093 \pm 0.008$ & 0.135 \\
$\mathrm{Fe}$ & $6.97 \pm 1.66$ & $7.59 \pm 1.69$ & 0.398 \\
$\mathrm{Ni}$ & $0.025 \pm 0.005$ & $0.033 \pm 0.006$ & 0.149 \\
$\mathrm{~Pb}$ & $0.034 \pm 0.004$ & $0.046 \pm 0.005$ & 0.029 \\
\hline
\end{tabular}

\section{References:}

Åkerblom, S., \& de Jong, J. (2017): Mercury in fur of Daubenton's bat (Myotis daubentonii) in Southern Sweden and Comparison to Ecotoxicological Thresholds. Bulletin of Environmental Contamination and Toxicology, 99(5), 561-566.

Appenzeller, B.M.R., Tsatsakis, A.M., (2012): Hair analysis for biomonitoring of environmental and occupational exposure to organic pollutants: state of the art, critical review and future needs. Toxicol. Lett. 210, 119-140.

Barclay R.M.R., and Jacobs D.S. (2011): Differences in the foraging behaviour of male and female Egyptian fruit bats (Rousettus aegyptiacus). Canadian Journal of Zoology 89(6):466-473.

Bartonička, T., Zukal, J., 2003. Flight Activity and Habitat Use of Four Bat Species in a Small
Town Revealed by Bat Detectors. Folia Zool. 52, 155-166.

Beernaert, J., Scheirs, J., Leirs, H., Blust, R., Verhagen, R., 2007. Non-destructive pollution exposure assessment by means of wood mice hair. Environ. Pollut. 145, 443-451.

Benda, P., Vallo, P., Hulva, P., \& Horáček, I. (2012). The Egyptian fruit bat Rousettus aegyptiacus (Chiroptera: Pteropodidae) in the Palaearctic: Geographical variation and taxonomic status. Biologia, 67(6).

Beyersmann, D., Hartwig, A., 2008. Carcinogenic metal compounds: recent insight into molecular and cellular mechanisms. Arch. Toxicol. 82, 493-512.

Dauwe, T., Bervoets, L., Blust, R., Pinxten, R., Eens, M., 2000. Can excrement and feathers of nestling songbirds be used as biomonitors for 
heavy metal pollution? Arch. Environ. Con Tox 39, 541-546.

D'Hav_e, H., Scheirs, J., Mubiana, V.K., Verhagen, R., Blust, R., De Coen,W., 2006. Nondestructive pollution exposure assessment in the European hedgehog (Erinaceus europaeus): II. Hair and spines as indicators of endogenous metal and as concentrations. Environ. Pollut. 142, 438448.

Gaisler, J., Zukal, J., ̌̌ehák, Z., Homolka, M., 1998. Habitat preference and flight activity of bats in a city. J. Zool. 244, 439-445.

Hernout, B. V., McClean, C. J., Arnold, K. E., Walls, M., Baxter, M., \& Boxall, A. B. A. (2016). Fur: A non-invasive approach to monitor metal exposure in bats. Chemosphere, 147, 376-381.

Herzig-Straschil B, Robinson GA. 1978. On the ecology of the fruit bat, Rousettus aegyptiacus leachi (A. Smith, 1829) in the Tsitsikama Coastal National Park. Koedoe 21:101-110.

Hickey, M. B. C., Fenton, M. B., MacDonald, K. C. \& Soulliere, C. (2001). Trace Elements in the Fur of Bats (Chiroptera: Vespertilionidae) from Ontario and Quebec, Canada. Bulletin of Environmental Contamination and Toxicology, 66: 699-706.

Jones, G., Jacobs, D. S., Kunz, T. H., Willig, M. R. \& Racey, P. A. (2009). Carpe noctem: the important of bats as bioindicators. Endangered Species Research, 1: 1-17.

Kalcounis-Rueppell, M. C., Payne, V. H., Huff, S. R. \& Boyko, A. L. (2007). Effects of wastewater treatment plant effluent on bat foraging activity in an urban stream system. Biology Conservation, 138: 120-130.

Kales, S.N., Christiani, D.C., 2005. Hair and metal toxicity. In: Tobin, D.J. (Ed.), Hair in
Toxicology: an Important Biomonitor. Royal Society of Chemistry, Cambridge, MA, pp. 125-158.

Kunz TH, Braun de Torrez E, Bauer D, Lobova T, Fleming TH. 2011. Ecosystem services provided by bats. Annals of the New York Academy of Sciences 1223:1-38.

Li, Z., Ma, Z., van der Kuijp, T.J., Zuan, Z., Huang, L., 2014: A review of soil heavy metal pollution from mines in China: Pollution and health risk assessment. Sci. Total Environ. 468-469, 843853.

Lučan, R. K., Bartonička, T., Benda, P., Bilgin, R., Jedlička, P., Nicolaou, H., Reiter, A., Shohdi, W.M., Salek,M., Rerucha, S., Uhrin, M., AbiSaid, M., Horáček, I.(2014). Reproductive seasonality of the Egyptian fruit bat (Rousettus aegyptiacus) at the northern limits of its distribution. Journal of Mammalogy, 95(5), 1036-1042.

Ma, W. (1996). 'Lead in Mammals', in W. N. Beyer, G. H. Heinz \& A. W. Redmon- Norwood (eds), Environmental Contaminants in Wildlife, Lewis Publication, Boca Raton, Florida, pp. 281-296

Marcheselli, M., Sala, L., Mauri, M., 2010. Bioaccumulation of PGEs and other trafficrelated metals in populations of the small mammal Apodemus sylvaticus. Chemosphere 80, 1247-1254.

McLean, C.M., Koller, C.E., Rodger, J.C., MacFarlane, G.R., 2009. Mammalian hair as an accumulative bioindicator of metal bioavailability in Australian terrestrial environments. Sci. Total Environ. 407, 35883596. 
Mickleburgh, S.P., Hutson, A.M., Racey, P.A., 2002. A review of the global conservation status of bats. Oryx $36,18-34$.

Monadjem A, Taylor PJ, Cotterill FPD, Schoeman MC. 2010. Bats of Southern and Central Africa: A Biogeographic and Taxonomic synthesis. University of Witwatersrand Press, Johannesburg, South Africa.

Nolet, B.A., Dijkstra, V.A.A., Heidecke, D., 1994. Cadmium in beavers translocated from the Elbe to the Rhine/Meuse estuary, and the possible effect on population growth rate. Arch. Environ. Con Tox 27, 154-161.

Payne, J., Francis, C. M. \& Phillips, K. (1985). A field guide to the mammals of Borneo. The Sabah Society and WWF Malaysia, Kota Kinabalu.

Pereira, R., Pereira, M.L., Ribeiro, R., Gonçalves, F., 2006. Tissues and hair residues and hispathology in wild rats (Rattus rattus L.) and Algerian mice (Mus spretus Lataste) from an abandoned mine area (Southeast Portugal). Environ. Pollut. 139, 561-575.

Pereira, R., Ribeiro, R., Gonçalves, F., 2004. Scalp hair analysis as a tool in assessing human exposure to heavy metals (S. Domingos mine, Portugal). Sci. Total Environ. 327, 81-92.

Sheta, B.M.; Abd El-Hamid, H.T. and El-Alfy, M. A. (2019): Human Health Risk via Cadmium Concentration in Different Tissues of Domesticated Japanese Quail (Coturnix japonica) and Wild Common Quail (Coturnix coturnix). CATRINA . 18 (1): 65-70.

Vermeulen, F., D'Hav_e, H., Mubiana, V.K., van den Brink, N.W., Blust, R., Bervoets, L., De Coen, W., 2009. Relevance of hair and spines of the European hedgehog (Erinaceus europaeus) as biomonitoring tissues for arsenic and metals in relation to blood. Sci. Total Environ. 407, 1775-1783.

Wickramasinghe, L. P., Harris, S., Jones, G. \& Jennings, N. V. (2004). Abundance and species richness of nocturnal insects on organic and conventional farms: effects of agricultural intensification on bat foraging. Conservation Biology, 18: 1283-129. 
